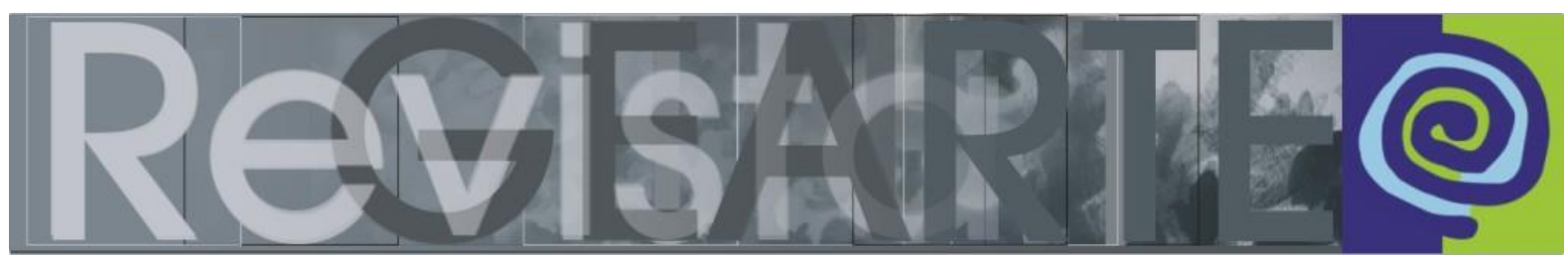

e-ISSN 2357-9854

\title{
Aisthesis: uma breve introdução à estética dos afetos
}

\author{
Renato Camassutti Bedore (Universidade Federal do Paraná - UFPR, \\ Curitiba/PR, Brasil)
}

\author{
Marcos Namba Beccari (Universidade Federal do Paraná - UFPR, \\ Curitiba/PR, Brasil)
}

\begin{abstract}
RESUMO - Aisthesis: uma breve introdução à estética dos afetos - Este artigo pretende apresentar um panorama introdutório de estudos sobre estética a partir do viés dos afetos. Nesse sentido, a estética é balizada pelos afetos humanos e não pela correspondência com algum critério de beleza (visão consolidada nos campos das artes e do design). Assim, propomos a estética como um estudo mais amplo, que trata de questões que abrangem a vida como um todo e se pauta em conceitos relacionados ao modo como somos afetados sensivelmente pelo mundo. Tal visão inicia-se com noções derivadas do pensamento sofista, passa pelo epicurismo e se desenvolve nas filosofias de Baruch Spinoza, David Hume e Friedrich Nietzsche. Por esse prisma, a dimensão estética é entendida como crucial e incontornável em nossa relação com o mundo.
\end{abstract}

PALAVRAS-CHAVE

Estética. Afetos. Design. Experiência.

ABSTRACT - Aisthesis: a brief introduction to the aesthetics of affections - This article intends to present an introductory panorama of aesthetic studies from the bias of affections. In this sense, aesthetics is marked by human affections and not by correspondence with some criterion of beauty (consolidated vision in the fields of arts and design). Thus, we propose aesthetics as a larger study, which deals with issues that cover life as a whole and is based on concepts related to how we are affected significantly by the world. Such a vision begins with notions derived from the sophist thought, passes through Epicureanism and is developed in the philosophies of Baruch Spinoza, David Hume and Friedrich Nietzsche. From this perspective, the aesthetic dimension is understood as crucial and unavoidable in our relationship with the world.

\section{KEYWORDS}

Aesthesis. Affections. Design. Experience.

A noção de estética, antes de ter sido associada com a arte e com o belo, derivou "do grego aisthesis ou aestesis, [...] [que] significa a capacidade de sentir o mundo, compreendê-lo pelos sentidos, é o exercício das sensações" (ALMEIDA, 2015, p. 134).

Para discorrer sobre a relação da estética com os afetos é pertinente retomar as bases do pensamento sofista, cuja preocupação não residia na correspondência do discurso com um conceito universal de verdade, e sim na autonomia do próprio discurso. Ou seja, para esses pensadores era mais importante a compreensão do que 
é, por exemplo, belo em um determinado momento e para um determinado público (compreensão que é construída e consolidada por meio de um discurso) do que propriamente a definição arbitrária do conceito de beleza.

\begin{abstract}
Ocupados em ensinar de que maneira o lógos podia ser usado eficientemente, ou seja, produzindo a persuasão do auditório ou minando a argumentação de um adversário, os sofistas se constituíram, ao final das contas, os primeiros professores de política, ou se quisermos, de "cidadania": o discurso é plástico, dirão eles, e pode ser moldado de inúmeras formas, mais ou menos adequadas para o momento (o kairós), que era o que de mais importante havia: perder ou não notar o kairós, a ocasião, impedia o sucesso do discurso (PAGOTTO-EUZEBIO, 2010, p. 206).
\end{abstract}

Nessa perspectiva, a estética seria balizada pelo homem (mais precisamente pelos afetos humanos) e não pela correspondência com uma verdade (ou um belo verdadeiro). Ou seja, algo seria denominado esteticamente agradável à medida que nos afeta sensivelmente de modo positivo.

Para exemplificar essa relação afetiva, apresentamos uma breve análise do texto Elogio a Helena, escrito pelo sofista Górgias. Em forma de um exercício argumentativo, Górgias tece uma série de pensamentos com o intuito de apresentar uma visão contrária ao senso comum dos gregos sobre Helena, personagem da llíada de Homero.

O sofista parte da duplicidade da sua imagem, representada no seguinte trecho: "[...] mulher que reúne, em uma só voz e em uma só alma, a crença dos que ouvem os poetas e o ruído de um nome que abriga a memória de infortúnios" (GÓRGIAS apud SALLES, 2014, p. 80), referindo-se à atração da sua beleza e o repúdio à sua imagem, ligada ao infortúnio da guerra.

Tal perspectiva parece estar bem alinhada com a ideia sofista de kairós (ocasião, momento oportuno), afinal, se não existe uma imagem coesa (que não possa ser refutada discursivamente) de Helena, a compreensão sobre ela fica à mercê do simples acaso que engendra as afeições provocadas pelos discursos. É essa prática poética (poíesis em grego significa ato de criação) que Górgias conjuga ao discurso, entendendo-o como um meio de provocar persuasão pelos afetos. 
Tendo em vista que nossos sentidos estão à mercê dos afetos (ou seja, sentimos as coisas na medida em que somos afetados por elas, e não na medida em que elas nos aproximam de uma verdade universal e irrefutável), uma mesma coisa pode nos afetar de maneira diferente em ocasiões diferentes. Alinhando-se a esse aspecto do conceito sofista de discurso, a conjuntura das palavras acerca de um fato pode gerar sensações agradáveis ou desagradáveis naqueles que as interpretam, uma vez que o afeto se "costura" no entremeio das interpretações estéticas que fazemos a partir do nosso contato com o mundo.

No viés afetivo, portanto, não faz sentido definir o que é "realmente" belo. Pensar a estética como forma de compreensão do mundo pelo exercício das sensações implica deixar "em aberto" a multiplicidade dos afetos. A estética, nesse viés, se relaciona mais com a noção de ocasião (kairós) e acaso do que com a de universalidade.

Hípias, outro importante sofista, traz reflexões interessantes acerca da beleza. Seu pensamento é depreciado no texto Hípias Maior, no qual Platão relata uma discussão entre Hípias e Sócrates sobre o que seria o conceito de beleza definitiva. O sofista dá a seguinte resposta: o belo é uma "jovem mulher". Ao escutar tal definição, Sócrates a refuta, pois ela não abarca todas as coisas belas do mundo. Entretanto, Hípias "não teve em mente apresentar uma definição rigorosa e lógica de beleza; apenas sugeriu um exemplo prototípico, um superlativo do belo e sua galanteria se dirigiu para o que the pareceu mais belo no mundo, o eterno feminino" (LEMOS, 2007, p. 100). Esse apontamento destaca a relatividade da beleza que o sofista buscou demonstrar. Pensar o belo como sendo uma jovem mulher solicita compreender de antemão que tal ideia é relativa, tendo em vista que para uma jovem ser considerada bela é necessário que exista alguém que a considere assim. Em outros termos, uma jovem só pode ser bela para determinado indivíduo e em determinada ocasião; enfim, ela é bela na medida em que afeta positivamente alguém.

Em suma, podemos inferir que o pensamento sofista contribuiu para a estética dos afetos ao priorizar a relação entre as sensações e o contexto no qual elas se manifestam, conforme sintetiza Beccari no seguinte trecho: 
É basicamente isto que, incomodando Sócrates, defendiam os sofistas: uma sensibilidade ao contexto, portanto ao acaso e às circunstâncias, como complemento e contrapartida necessários à polissemia inelutável. Com tal sensibilidade, não se preenchem mais as condições da interpretação mediante codificações parciais (em função de uma ordem geral), e sim por meio do diálogo e da ressignificação circunstancial (BECCARI, 2016, p. 124).

Isso posto, é possível dar continuidade ao percurso da estética dos afetos relacionando-a com a filosofia epicurista. Para Epicuro, filósofo grego do período helenístico, o bem se encontra na ideia de prazer e pode ser praticado através de atividades cultivadas em seu conhecido Jardim.

\begin{abstract}
O epicurismo coloca o sumo bem no prazer. Na sua forma mais rigorosa, restringe-se a buscar o prazer negativo que consiste na ausência da dor. $O$ ideal do sábio é a ataraxia, a paz imperturbável do espírito. Quanto aos prazeres positivos limitam-nos aos absolutamente necessários (TRINGALI apud ALMEIDA, 2011, p. 640).
\end{abstract}

Desse modo, parece ficar indicado o caminho para a compreensão de uma estética epicurista na percepção dos afetos associados ao prazer, que seriam identificados como consequências de experiências agradáveis. Esse processo nos proporcionaria a capacidade de distinguir o que nos faz bem (prazeres simples) do que nos faz mal (dor e sofrimento).

[...] a paixão (ou afecção) é o reflexo no indivíduo das qualidades próprias da realidade. $O$ modo como algo o afeta produz nele uma sensação referente às qualidades éticas e materiais da coisa que é sentida. Pelas afecções o ser humano sabe distinguir o que lhe é bom ou mal na experimentação ou vivência do mundo, desde que ele tenha a sensibilidade necessária para perceber esse mundo (ROSSETTI, 2014, p. 128).

Por conseguinte, os afetos aqui seriam compreendidos como um caminho para se chegar a uma vida feliz, mais especificamente através da compreensão das consequências afetivas que conformam nossas experiências. Sendo consequência da nossa relação com o mundo por via dos nossos sentidos, o prazer seria visto como índice de sensações agradáveis e a dor, de sensações desagradáveis, ou seja, a sensação estética atuando como prerrogativa do conhecimento.

Nesse momento é possível afirmar que o estudo da estética pelo entendimento dos afetos está preocupado com questões amplas e que se referem à vida como um todo, não apenas à contemplação da beleza. Por esse prisma, a compreensão estética seria crucial e incontornável em nossa relação com o mundo. 
De acordo com a filosofia epicurista, portanto, somos dotados de uma habilidade que nos permite sentir e conhecer as coisas do mundo. Tais coisas do mundo não indicam, por sua vez, uma verdade universal ou metafísica, mas sim uma concepção de mundo mais próxima daquela pensada pelos sofistas: o que nos afeta apenas afeta a cada um de forma singular, em nosso contato com o mundo, de maneira simplesmente oportuna ou inoportuna.

Com a construção da estética dos afetos pautada, até aqui, na ideia de kairós dos sofistas e nas sensações agradáveis, segundo Epicuro, advindas de afetos prazerosos, torna-se oportuno elencar na sequência o entendimento de Baruch Spinoza, filósofo do século XVII. Assim como os epicuristas, Spinoza também propunha uma filosofia orientada a uma vida alegre e baseada no cultivo de prazeres simples. Com isso, desenvolveu toda a sua linha de pensamento pautando-se no entendimento dos afetos como mecanismos que promovem nossa aderência ao mundo.

Para compreender tal "aderência" é necessário esclarecer brevemente um dos aspectos do "monismo" que sustenta a filosofia spinozista. O dualismo entre espírito e corpo, apresentada de maneira enfática por seu contemporâneo René Descartes, era frontalmente combatida por Spinoza, com o argumento de que espírito e corpo eram uma coisa só, sendo o "[...] corpo o objeto do espírito; o espírito, a ideia do corpo" (ONFRAY, 2009, p. 257).

Tal relação entre o espírito e o corpo se daria como uma via de mão dupla: enquanto o nosso corpo é afetado de diferentes formas, níveis e intensidades, vamos formando ideias acerca das situações que nos trazem alegrias e as que nos trazem tristezas. Esse conjunto de ideias é responsável por formar o nosso espírito, que por sua vez interfere no modo como o nosso corpo é afetado.

Por afeto compreendo as afecções do corpo, pelas quais sua potência de agir é
aumentada ou diminuída, estimulada ou refreada, e, ao mesmo tempo, as ideias
dessas afecções. Assim, quando podemos ser a causa adequada de alguma
dessas afecções, por afeto compreendo, então, uma ação (SPINOZA, 2007, p. 98).

Com isso em vista, para Spinoza afeto é o que nos acontece concomitantemente ao nosso contato com as coisas do mundo. Esse mecanismo seria inescapável, pois para o filósofo seríamos o resultado de uma constante relação 
que se constrói por meio dos afetos e que nos torna capazes de nos compreender e de nos imaginar.

Tal relação não se daria de modo unilateral, pois imaginamos o mundo e a nós mesmos na medida em que somos afetados pelas coisas e também as afetamos. Trata-se, portanto, de um mecanismo de conhecimento que nos permite "[...] saber quem somos, o que somos, como pensamos, quais afecções nos trabalham, a maneira como as paixões nos habitam, de que maneira o desejo nos atormenta" (ONFRAY, 2009, p. 248).

Para ele, "o corpo é afetado por paixões que aumentam sua potência de agir ou a diminuem" (ONFRAY, 2009, p. 260), ou seja, existem afetos capazes de nos alegrar (isto é, como fonte de aumento da nossa potência vital) e outros que nos entristecem (como fonte da diminuição da nossa potência vital). É importante evidenciar que a ideia de potência incluída nesse contexto se refere à vida, como vontade de viver, portanto em consonância com a perspectiva epicurista.

Da mesma forma, para Spinoza o conhecimento dos afetos provoca impactos significativos:

\footnotetext{
Informado do seu lugar no mundo, ele [o homem] o aceita sabendo que dispõe de uma margem de manobra muito reduzida e limitada, mas suficiente para produzir imensos efeitos: saber que se pode querer a Alegria e recusar a Tristeza para orientar seu desejo no sentido do conhecimento das verdades que geram a beatitude (ONFRAY, 2009, p. 262).
}

Não obstante, o que Spinoza parece propor é que pelo conhecimento seríamos capazes de converter afetos tristes (passivos) em afetos alegres (ativos). Isso porque, "Na medida em que a mente compreende todas as coisas como necessárias, ela tem um maior poder sobre seus afetos" (MARTINS, 2000, p. 193).

Com efeito, o "conhecimento" valorizado por Spinoza não envolve qualquer tipo de conhecimento, pois se refere especificamente ao conhecimento acerca dos nossos afetos. Tal tipo de conhecimento é categorizado pelo filósofo como sendo de "terceiro gênero" (o mais coeso de todos os tipos de conhecimento), e diz respeito à compreensão da singularidade dos afetos em determinada ocasião, em sentido oposto ao da universalidade da razão (predominante na filosofia ocidental). 
Nesse ponto, o pensamento spinozista encontra consonância com a ideia de kairós dos sofistas, dado que, para o pensador do século XVII, é importante conhecermos a dinâmica "ao acaso" de nossos afetos "[...] a fim de favorecermos nossos encontros, transformando causas externas em nosso favor, tornando-nos não mais causas parciais, mas causas adequadas de nossas ações" (MARTINS, 2000, p. 190).

Seguindo com a construção da linha de raciocínio da estética dos afetos, convém revisar ainda o pensamento do empirista escocês David Hume, do século XVIII. Assim como Kant, Hume parte do pressuposto de que a sensação estética não representa a essência das coisas: nada é naturalmente agradável ou desagradável. Quem faz essa distinção somos nós, a partir de nossas interpretações sensíveis (sensações e emoções) que são provocadas por nossas experiências. Entretanto, o filósofo escocês refuta a compreensão kantiana de que o juízo estético se sustentaria como uma "intuição" coletiva, isto é, um fato universal que proporcionaria certa harmonia entre as faculdades humanas. Para Hume, tal fator universal não pode ser induzido de nossas relações empíricas.

Para o filósofo, as ideias não são confirmáveis, pois nossa compreensão do mundo não serve para adequar o mundo às nossas ideias, mas o contrário. Tal compreensão poderia ocorrer de duas formas: pela "impressão" (aqui vista como correspondente às sensações), e pela "ideia" (aqui vista como um conceito derivado de uma crença).

\footnotetext{
Todas as ideias, especialmente as abstratas, são naturalmente fracas e obscuras: o intelecto as apreende apenas precariamente, elas tendem a se confundir com outras ideias assemelhadas, e mesmo quando algum termo está desprovido de um significado preciso, somos levados a imaginar, quando o empregamos com frequência, que a ele corresponde uma ideia determinada. Ao contrário, todas as impressões, isto é, todas as sensações, tanto as provenientes do exterior como as do interior, são fortes e vívidas; os limites entre elas estão mais precisamente definidos, e não é fácil, além disso, incorrer em qualquer erro ou engano relativamente a elas (HUME, 1999, p. 28-29).
}

Essa diferença na valoração dos tipos de compreensão é defendida por Hume com base em seu entendimento sobre a ligação entre nós e o mundo, indicada com a noção de "relação". Nesse prisma, as impressões seriam diretamente ligadas às relações, pois são geradas concomitantemente ao nosso contato com o mundo; já as ideias não se ligam diretamente às relações, pois derivam das impressões e ainda 
solicitam elementos externos (outras ideias). Sendo assim, somente a impressão configura uma relação concreta com alguma coisa no mundo, ou seja, um encontro casual e singular.

Avançando ainda no empirismo humeano, o mecanismo de associação entre as ideias (compreensão racional) e as impressões (compreensão estética) é o que o filósofo concebe por "imaginação". Mais precisamente, o hábito mental da atribuição de uniformidades na repetição de impressões seria incumbência das ações da imaginação.

[...] cabe à imaginação refletir a paixão, fazê-lo ressoar, fazer com que ultrapasse os limites de sua parcialidade e de sua atualidade naturais. Hume mostra como os sentimentos estéticos e os sentimentos morais são assim constituídos: paixões refletidas na imaginação, que se tornam paixões da imaginação. Ao refletir as paixões, a imaginação libera-as, estira-as infinitamente, projeta-as para além de seus limites naturais (DELEUZE, 2002, p. 211).

Nesse mecanismo apontado por Deleuze, parece ficar claro a capacidade que a imaginação teria de potencializar paixões oriundas dos afetos e, por conseguinte, conferir significado a elas. Por meio da reflexão, ela seria capaz de produzir uma sensação de "apaixonar-se" pelas coisas e pelo mundo.

Noutras palavras, trata-se de pensar nos afetos como uma forma de compreender e intensificar a vida; ou, nos termos de Nietzsche, como um modo de "afirmar a vida" no seu sentido mais amplo. Rogério de Almeida procura explicar as bases do pensamento nietzscheano com o entendimento de que, "[...] para Nietzsche, a existência só se justificaria como fenômeno estético" (ALMEIDA, 2015, p. 135).

Significa dizer que nossa vida só faz sentido por meio da perspectiva dos afetos. Dessa forma, a compreensão de mundo de Nietzsche se aproxima da de Spinoza: para ambos, o registro sensível e o racional são inseparáveis e estão ancorados a um único mundo.

[...] só há um mundo, que não é nem somente sensível nem somente inteligível; nem o mundo do além, nem o das aparências; um só mundo portanto inteligível e sensível. Nele somos então de corpo e alma: um não é fundamento do outro, tampouco o inverso. Imersos neste único mundo, imanente, sem transcendência, conhecemos as coisas em perspectiva: não estamos separados do que conhecemos, não conhecemos o mundo a partir de um outro lugar, imaterial, inteligível, puramente racional (MARTINS, 2000, p. 187). 
Dessa forma, Nietzsche combate a metafísica e, no lugar dela, confere ao âmbito sensível um lugar de protagonismo em nossa compreensão do mundo. Nesse prisma, assim como na visão spinozista, o que somos, pensamos e sentimos é consequência do modo como nosso corpo é afetado em nosso contato com o mundo, conforme o filósofo alemão argumenta no seguinte trecho de seu livro Assim falava Zaratustra:

\footnotetext{
O corpo é uma grande razão, uma multiplicidade com um só sentido, um estado de guerra e paz, um rebanho e seu pastor. Essa pequena razão a que dás o nome de teu 'espirito', ó meu irmão, é apenas um instrumento do teu corpo, e um bem pequeno instrumento, um brinquedo da tua grande razão. [...] O eu sente alegria e se pergunta como há de fazer para experimentar ainda muitas vezes a alegria - é para esse fim que lhe deve servir 0 pensamento (NIETZSCHE apud MARTINS, 2000, p. 189).
}

Com base nessa ideia de unicidade do mundo, Nietzsche defende que é preciso aceitar o mundo de forma integral, ou seja, aceitar tanto as coisas agradáveis quanto as desagradáveis, e a isso ele dá o nome de amor fati (amor pelo próprio destino). Esse conceito é sintetizado por Almeida da seguinte forma: "[...] a questão nietzscheana é se afirmamos incondicionalmente a vida a ponto de afirmar também o que ela possui de pior. Querer a eterna repetição do instante é a prova do amor fati." (ALMEIDA, 2015, p. 27).

Vale reforçar que esse imperativo nietzscheano tem o poder de potencializar nossos encontros estéticos, pois afirmar o que há de pior em nossa vida solicita certa sensibilidade estética "apurada", afinal o conceito de amor fati implica um gosto permanente pela vida. Nas palavras do próprio filósofo: “[...] não querer nada além do que é, nem atrás de si nem na frente de si, nem em séculos e séculos, não se contentar de suportar o inelutável e ainda menos dissimulá-lo [...], mas amá-lo..." (NIETZSCHE apud MARTINS, 2000, p. 192-193). Portanto, vale mais nesse pensamento a aceitação da situação presente, singular e irreversível, descartando a vontade de querer mais do que o mundo está oferecendo, e com isso "tornar-se o que se é".

A compreensão dos conceitos de "amor fati" e "eterno retorno" parecem estar diretamente ligadas ao modo como somos afetados esteticamente. Com o entendimento de que o mundo é da forma que é, em seus melhores e piores aspectos, reforça-se a ideia de que a forma como somos afetados pelas coisas não é 
determinada pelas coisas (essência), mas pela própria relação que se conjuga entre nós e o mundo. Dessa forma, toda ação que fazemos no mundo, assim como a nossa própria existência, é relativa ao modo como nos relacionamos afetivamente com o mundo. Significa também que a nossa compreensão acerca dos nossos afetos (o que e como nos afeta) pode exercer influência em nossas relações com o mundo.

Assim como Spinoza, Nietzsche entende que os afetos são um meio de conhecimento sobre nós mesmos e sobre o mundo. Por conseguinte, com a compreensão do modo como o que nos afeta provoca determinadas sensações e emoções em nosso corpo, seríamos capazes de aumentar nossa potência perante a vida. Trata-se de colocar a nosso "[...] favor o acaso, os encontros inevitáveis, de modo a que esta relação momentânea aumente [nossa] potência de agir, de pensar, afetando-o de alegria" (MARTINS, 2000, p. 185).

Daí que o filósofo do século XIX aponta para o conceito de "vida como obra de arte" como um meio de afirmação da vida, isto é, uma afirmação "[...] por meio dos sentidos que atribuo à minha trajetória, pela somatória das escolhas que faço com o fortuito da existência" (ALMEIDA, 2015, p. 182). É "[...] entregar-se ao jogo do mundo, cumprir o vaticínio de nos tornarmos os poetas de nossas vidas" (NIETZSCHE apud ALMEIDA, 2015, p. 149), e dessa forma cultivar uma abertura ao acaso dos encontros, em suas mais diversas potencialidades, fomentando a intensificação de nossos "gostos".

\begin{abstract}
Esse 'gosto', pelo qual a filosofia trágica designa simultaneamente o que é chamado ora de talento, ora de gênio, ora potência criadora ou capacidade produtiva, não significa uma aptidão em transcender o acaso em criações que escapariam ao acaso, mas uma arte (originalmente sofística) de discernir, no acaso dos encontros, aqueles que dentre eles são agradáveis: arte, não de 'criação', mas de antecipação (prever, por experiência e delicadeza, os bons encontros) e de retenção (saber 'reter' sua obra num desses bons encontros, o que significa que se pode apreender no voo o momento oportuno) (ROSSET, 1989, p. 183).
\end{abstract}

A citação acima aponta para uma síntese da estética dos afetos desenhada aqui. O caminho indicado é o de que, pela compreensão sensível de nossos afetos, somos capazes de potencializar nossa aderência ao mundo tal como ele se apresenta a nós. Trata-se do cultivo dos "gostos", o que equivale ao que Almeida denomina "[...] transcriação estética, [como sendo uma] manipulação casual das aparências, 
instantâneos de uma vida fugaz que se tornou indiferente à duração do mundo" (ALMEIDA, 2015, p. 133).

\section{Considerações finais}

Com esse desenvolvimento da estética vista pelo ponto de vista dos afetos, é possível sintetizar tal visada da seguinte forma: o ponto em comum de todos os filósofos ligados a esse viés é a constatação de que os processos estéticos são individuais e, portanto, se desenvolvem na interação de cada indivíduo com o mundo (descartando assim toda e qualquer possível relação da estética com uma verdade universal). Outro ponto em comum é a ideia de que a compreensão de tais processos ocorre no âmbito sensível, ou seja, de forma imediata e imanente. Por fim, todos convergem na constatação de que tudo isso ocorre ao acaso, isto é, sem a determinação de uma causa ou finalidade.

Pensar a estética nesses termos significa uma abertura aos temas de interesse da mesma. Tal constatação se encontra em consonância com o atual momento do design e da arte (Cf. BECCARI, 2016; BECCARI; ALMEIDA, 2016). Em dias nos quais a experiência estética significativa e individual ganha mais relevância projetual em contrapartida a uma experiência pragmática e replicada, compreender os entremeios das formações dos afetos se faz urgente. Acreditamos que o panorama introdutório apresentado nesse artigo pode proporcionar um terreno fértil para demais estudos acerca da estética e dos afetos.

\section{Referências}

ALMEIDA, Rogério de. O mundo, os homens e suas obras: filosofia trágica e pedagogia da escolha. 2015. 204 f. Tese (Livre docência) - Faculdade de Educação, Universidade de São Paulo, São Paulo. 2015.

ALMEIDA, Rogério de. O imaginário trágico de Ricardo Reis: uma educação para a indiferença. Educação e Filosofia, v. 25, n. 50, p. 635-654, jul./dez. 2011.

BECCARI, Marcos; ALMEIDA, Rogério. O cotidiano estético: considerações sobre a estetização do mundo. Revista Trágica: estudos de filosofia da imanência, Rio de Janeiro, v. 9, n. 3, p. 10-26, 2016.

BECCARI, Marcos. Articulações simbólicas: uma nova filosofia do design. Teresópolis, RJ: 2AB, 2016. DELEUZE, Gilles. A ilha deserta. São Paulo: Editora lluminuras Ltda, 2002.

HUME, David. Investigação sobre o entendimento humano. São Paulo: Editora UNESP, 1999.

LEMOS, Celso. Atualidade do diálogo Hípias Maior, de Platão. Kléos, v. 11/12, p. 93-142, jul. 2007/jul. 2008. 
MARTINS, André. Nietzsche, Espinosa, o acaso e os afetos: encontros entre o trágico e o conhecimento intuitivo. O Que nos Faz Pensar, Rio de Janeiro, v. 11, n. 14, p. 183-198, 2000.

ONFRAY, Michel. Contra-história da filosofia: libertinos barrocos III. São Paulo: Editora WMF Martins Fontes, 2009.

PAGOTTO-EUZEBIO, Marcos Sidnei. A Filosofia, a cidade, a Paideia: os antigos contemporâneos. Páginas de Filosofia, v. 2, n. 1, p. 195-214, jan./jun. 2010.

PAGOTTO-EUZEBIO, Marcos Sidnei. O corpo de Helena e o texto de Isócrates. Revista Internacional d'Humanitats, v. XIV, p. 73-80, 2011.

ROSSET, Clément. Lógica do pior. Rio de Janeiro: Espaço e Tempo, 1989.

ROSSETTI, Ricardo. Amor e amizade: a 'boa educação' para uma vida justa em Epicuro. In: Marcos Sidnei Pagotto-Euzébio; Rogério de Almeida. (Orgs.). Nós, os antigos: XI Semana de Estudos Clássicos da FEUSP. São Paulo: Képos, 2014. p. 125-152.

SALLES, Lucio Lauro B. M. Górgias Leontino da palavra como Phármakon. 2014. 119 f. Dissertação (Mestrado em Filosofia) - Instituto de Filosofia e Ciências Sociais, Universidade Federal do Rio de Janeiro, Rio de Janeiro.

SPINOZA, Baruch. Ética. Tradução de Tomaz Tadeu. Belo Horizonte: Autêntica, 2007.

\section{Renato Camassutti Bedore}

Universidade Federal do Paraná, formado em Desenho Industrial com ênfase em Programação Visual pela UNESP em 2010 e mestrado regular em Sistemas da Informação no PPGDesign da UFPR, com início em março de 2016.

E-mail: renatobedore080@gmail.com

Currículo: http://lattes.cnpq.br/4695653019325130

\section{Marcos Namba Beccari}

Professor do Departamento de Design da Universidade Federal do Paraná (UFPR). Doutor em Educação pela Universidade de São Paulo (USP).

E-mail:marcosbeccari@usp.br

Currículo: http://lattes.cnpq.br/1779138299755162

Recebido em 8 de junho de 2017 Aceito em 23 de outubro de 2017 